\title{
Acute Myocardial Injury: A Perspective on Lethal Reperfusion Injury
} Kingma JG*

Department of Medicine, Laval University, Quebec, Canada

*Corresponding author: Dr. Kingma JG, Research Center of the Quebec Heart and Lung Institute, Laval University, 2725 Chemin Ste-Foy, Ste-Foy, Qc G1V 4G5, Canada, Tel: 418 656-8711/5440; Fax: 418 656-4509; E-mail: john.kingma@fmed.ulaval.ca

Received date: August 17, 2017; Accepted date: September 04, 2017; Published date: September 11, 2017

Copyright: @ 2017 Kingma JG. This is an open-access article distributed under the terms of the Creative Commons Attribution License, which permits unrestricted use, distribution, and reproduction in any medium, provided the original author and source are credited.

\begin{abstract}
Acute myocardial infarction contributes significantly to mortality in patients with coronary artery disease. Timely reperfusion of an infarct-related artery within a reasonable time-frame after acute coronary occlusion continues to be the most effective intervention in patients to reduce morbidity and mortality. However, restoration of blood flow to reversibly injured cardiocytes (and other cardiac cell types) within the under-perfused region may also provoke additional damage-commonly referred to as lethal reperfusion injury. Debate has gone on, and continues regarding the existence of reperfusion injury and the pathways that are solicited. Consequently, findings from fundamental science studies have facilitated identification of therapeutic targets that may benefit patients with acute coronary syndromes. This review examines evidence from basic science and clinical studies that support the premise of cardiac injury caused by reperfusion. Pathogenesis of post-ischemic cellular injury is discussed along with potential interventions (pharmacologic and non-pharmacologic) currently being used to improve clinical outcomes.
\end{abstract}

Keywords: Lethal reperfusion injury; Ischemia; Cellular protection; Coronary collateral vessels; Microcirculation; Blood flow; Ischemic conditioning

\section{Introduction}

The notion of lethal reperfusion injury in the heart implies that injury ensues to viable myocytes at the time of reperfusion, over and above, the cellular damage normally attributed to the initial ischemic event. The occurrence of reperfusion injury may be inevitable but restoration of blood flow to the infarct-related artery is critical to ensure salvage of reversibly injured myocytes within the area at risk. Debate concerning prevalence of reperfusion injury continues but no true experimental model is presently available to distinguish damage caused by restoration of flow to the perfusion bed of the infarct related artery compared to that present at the end of ischemia. Advocates of the reperfusion injury theory argue that antecedent ischemia in addition to a yet unidentified unfavourable component of reperfusion compromises recovery of cardiac function; however, conclusive evidence for reperfusion-mediated pathology remains to be established [1-4]. Various forms of reperfusion injury can include myocardial and vascular stunning, microvascular injury and no-reflow, arrhythmias, etc. Herein, we briefly consider the evidence regarding the conundrum of reperfusion injury along with interventions that potentially limit its lethal consequences in patients.

For this review, fundamental science and clinical reports were searched using several databases (i.e. PubMed, MEDLINE, Google Scholar); articles concerning reperfusion injury (lethal and otherwise), ischemia-reperfusion injury, apoptosis, microvascular injury, ischemic conditioning and different combinations thereof were consulted. In addition, we referred to data from a number of our own experiments on the subject.

Timely reperfusion of the infarct-related artery continues to be the most effective means to limit development of cellular necrosis. A plethora of pharmacologic and non-pharmacologic interventions administered at various times before and during ischemia, or at the time of coronary reperfusion provides some relief against ischemic injury [5-7]; however, overall clinical usefulness remains controversial.

\section{Myocardial Ischemia}

Diffuse coronary artery disease (i.e. atherosclerosis, arteriosclerosis, etc.) most often results in an acute coronary event (i.e. plaque rupture, thrombosis, platelet emboli, vasoconstriction, etc.) that leads to arterial occlusion; immediate concerns consist of hemodynamic and electrocardiographic effects. Since myocardium is highly dependent on blood flow for delivery of oxygen (almost $70 \%$ of blood-borne oxygen is extracted) and nutrients, any interruption in blood flow results in a marked disruption of cardiac function. While myocardial ischemia is a consequence of an imbalance between oxygen supply and demand, failure to remove high-energy phosphate metabolites and carbon dioxide also plays an important role.

Physiopathology of acute myocardial infarction is well established [8-10]. Early experiments documented two kinds of ischemic injury:

- Reversible, where myocytes survived periods of ischemia less than 15 minutes duration.

- Irreversible, with no capacity for myocyte recovery.

In reversibly injured myocytes early restoration of blood flow results in complete recovery of cellular function with no discernible sequelae. On the other hand, irreversible myocyte injury (i.e. necrosis) produces marked cellular ultrastructural changes such as cell swelling, denaturation of intracellular proteins, membrane disruption, presence of contraction bands and mitochondrial calcification, etc. due to metabolic failure and rapid depletion of high-energy stores [11-13]. Other modes of cellular injury and death (i.e. apoptosis, autophagy, oncosis) also merit attention. Conditions that control the transition from one status to the other have been widely debated $[14,15]$. Recently, Jennings suggested, "myocytes are irreversibly injured when they fail to survive after restoration of the environment to normal" [3]. Furthermore, loss of structural integrity accompanied by replacement 
with scar tissue is an important consideration. Timing of cell injury and location across the myocardial wall are also important criteria; for the most part, potentially salvageable myocytes are localised in the midmyocardial and epicardial layers. This observation led to the realization that ischemia-induced myocyte injury follows a transmural gradient across the ventricular wall following acute coronary occlusion [16,17]. Earlier studies also hypothesized that distinct states of flow reduction and ischemic injury affect myocyte vulnerability to damage $[18,19]$. These conditions are important as successful reperfusion therapy necessitates that rapid restoration of blood flow must be achieved to impede development of a transmural infarct. Failure to restore blood flow can be caused by microvascular dysfunction; it is important to remember that significant damage also occurs to the coronary vasculature during ischemia that can influence functional recovery of different cellular components of the myocardial architecture. In addition, while myocytes comprise more than $80 \%$ of ventricular mass, other cell types integral to cardiac function (i.e. intraand extra-cardiac sympathetic/parasympathetic neurons) are also negatively affected by ischemia; their injury threshold is not well established [20].

Cardiocytes and cardiac neurons conceivably share common survival pathways but this remains to be proven [21]. Interestingly, viable nerves that course over an infarcted region tend to remain so since oxygen and energy needs can be fulfilled via blood from extra cardiac sources [22]. Nonetheless, successful restoration of blood flow within the infarct-related artery and to ischemic myocardium is essential to limit untoward effects on cardiac performance.

\section{Microcirculation and collateral vessels in ischemia}

In the heart, reductions in oxygen delivery are generally countered by increases in blood flow or increased capillary density; this was initially described by Krogh [23] who documented that under resting conditions only a small number of coronary capillary vessels were open. He put forward that increases in oxygen demand could promote recruitment of additional capillary vessels; the extent of this response was dependent on factors such as topography of the vascular network $[24,25]$, vascular tone $[26,27]$, and mechanical properties of red blood cells. [28] In addition, disruptions in oxygen supply and demand stimulated growth of coronary collateral vessels that can augment myocardial perfusion and thereby prevent further myocardial necrosis within the ischemic zone. The coronary collateral circulation is a recognized alternative source of blood supply to jeopardized myocardium [29,30]. Growth of collateral vessels is highly regulated over an extended period [31,32]; this was confirmed in dogs subject to repetitive, brief coronary occlusions [33]. The notion of recruitable, newly formed coronary collateral vessels at onset of ischemia to preserve myocyte viability is not completely accurate; it would seem more reasonable that pre-existing arterioles/capillaries are recruited under ischemic conditions. A host of factors (i.e. intramyocardial tissue pressure, coronary perfusion pressure, location, etc.) are involved in recruitment of existent collateral vessels within the ventricular wall [34]. Restoration of coronary perfusion pressures combined with reduced extravascular tissue pressures could explain, in part, the existence of patchy infarcts that are often observed in reperfused hearts.

Opening of coronary collateral channels in humans during coronary occlusion and during ischemic preconditioning has been reported [35-37]. More specifically, opening of coronary collateral vessels in conditioned myocardium has been associated with a marked reduction of ST segment elevation during repeated coronary occlusions. On the other hand, Tomai and co-workers could not confirm these findings during coronary angioplasty in patients with STEMI [38]. The inability to show a positive relation between myocardial tissue viability and improved blood flow at the level of the microcirculation post-ischemia may be due to the lack of sensitivity of currently employed techniques to measure spatial distribution of blood flow within the deeper myocardial layers. Animal studies to evaluate recruitment of coronary collateral circulation are sparse; one study in rabbits documents a trend to improved micro vessel blood flow produced by ischemic conditioning [39]. However, it is not clear that ischemic preconditioning preserves coronary vasodilator reserve [40,41].

\section{Consequences of Reperfusion of the Infarct-Related Artery}

\section{Lethal reperfusion injury}

Lethal reperfusion injury refers principally to myocyte death related to reperfusion rather than the preceding ischemia [42]. Restoration of arterial blood flow to the infarct-related artery can unequivocally reduce the extent of ischemic myocyte damage; however, questions remain regarding whether further damage occurs in already compromised myocytes within, or adjacent to, the ischemic area. Myocardial contractile stunning is considered a clear example of functional reperfusion injury and was first described in canine studies by Heyndrickx and colleagues [43]; they showed that reversibly injured myocardium did not contract as efficiently after reperfusion of the infarct-related artery. Use of oxygen-free radical scavengers at onset of reperfusion positively influenced post-ischemic contractile dysfunction and afforded significant myocyte protection [44,45]. An impressive number of studies have examined the phenomenon of severe myocyte injury stimulated by reoxygenation (i.e. oxygen paradox); however, it is not clear whether the oxygen paradox manifests injury produced during the period of oxygen depletion [46].

\section{No-reflow phenomenon}

No-reflow describes the inability to restore blood flow to tissues even after reopening of the infarct-related artery [47], this phenomenon is not exclusive to the heart and has also been described in other major organs $[48,49]$. In the heart, the area of no-reflow is principally confined to the anatomic risk zone (i.e. underperfused region). Causes of no-reflow comprise ultrastructural alterations (i.e. cell swelling, membrane gaps, etc.) within the microvasculature that worsen despite restoration of patency in the infarct-related vessel [50,51]. No-reflow is not considered to be a primary contributor to cell necrosis [52]; anatomic studies indicate that irreversible myocyte injury occurs before microvascular damage [53]. Reopening of an infarct-related artery exacerbates this phenomenon and is characterized by loss of vascular hyperemia (i.e. blood flow reserve) and blood flow over time within the ischemic region [54, 55]. Reduced vasodilator responses in larger conductance vessels (i.e. epicardial arteries) with extended durations of ischemia also contribute to impaired post-reperfusion blood flow [56-58]. Finally, no-reflow likely affects post-ischemic myocyte healing by limiting accessibility of inflammatory cells to the ischemic zone, and contributes to infarct expansion, ventricular dilatation and remodeling [59]. Involvement of neutrophils, and other inflammatory cell types, in lethal reperfusion injury has previously been examined by Vinten-Johansen [60]. 
During an acute ischemic event, the need to restore coronary patency is imperative not only to limit damage at the level of myocytes but also of the coronary microcirculation. Different interventions, either pharmacologic or not, have been studied; for example, primary Percutaneous Coronary Interventions (PCI) are used to reopen the infarct-related artery but they also provoke the release of microparticulate debris and platelet aggregates and thereby cause further injury downstream within the microvasculature [61,62]. Micro embolization during early reperfusion might be involved in development of injury, but it can also be a confounder to impede salvage of ischemic myocardium [63-65]. Recently, Skyschally and colleagues demonstrated a significant increase in infarct size in a porcine model of ischemia-reperfusion when microspheres were injected into the infarct-related artery immediately upon reperfusion [65]. They intimated that additional damage from microembolization occurs within a 'border zone' found within the anatomic risk area following arterial occlusion [66]. The degree and potential importance of injury due to micro-emboli (comprising debris from plaque fissure or rupture) in humans after PCI is probably underestimated [67]; this is probably also the case for release of soluble vasoactive substances post-PCI from injured vascular endothelium $[68,69]$.

At the level of the microvasculature ultrastructural changes (i.e. cell swelling, membrane gaps, etc.) can contribute to myocyte damage $[47,70]$; however, the degree of damage varies across the ventricular wall. Microvascular damage could contribute to irreversible myocyte injury since blood flow, even after restoration of patency to the infarctrelated artery, is impeded to reversibly injured myocytes. Understanding different factors that control post-ischemic coronary capillary blood flow across the myocardial wall also remains an important challenge. It is clear that impairment of the microcirculation or larger vessels immediately upstream of the microcirculation, in various pathologies (i.e. hypertension, cardiomyopathy, myocardial infarction) plays a crucial role in cellular viability and eventual recovery of ventricular performance.

\section{Myocyte injury and death}

Loss of myocytes due to ischemia is not uniform across the myocardial wall; different modes of cellular injury: 1) Apoptosis: cell death Type I; 2) Autophagy: cell death Type II; 3) Oncosis: spontaneous cell death; and 4) Necrosis are described [71,72]. In apoptosis, the integrity of the plasma membrane remains intact until the late stages of cell death; however, in necrosis plasma membranes rupture along with swelling of organelles and loss of intracellular content occurs early in the process [15,73]. Morphological characteristics of apoptosis include cell rounding, pyknosis, karyorrhexis and membrane blebbing. Intrinsic (mitochondrial) and extrinsic (death receptor) pathways are believed to mediate apoptosis [74]. Though essential during cardiac development, apoptosis is associated with ischemic heart disease, reperfusion injury, cardiomyopathy and heart failure [75]; the contribution of apoptosis to reperfusion injury remains the subject of ongoing debate [76,77]. Intracellular signalling pathways, along with morphologic, biochemical and molecular pathways responsible for regulation of apoptosis in cardiocytes have recently been discussed $[14,15,78]$. Ohno and coworkers postulated that myocyte damage during ischemia-reperfusion progressed from a reversible oncosis state to irreversible oncosis with or without DNA fragmentation [79]. Microscopic features of oncosis is well demonstrated for in situ evolving myocardial infarcts; this is not the case for apoptotic necrosis $[80,81]$. On the other hand, autophagy allows the cell deprived of essential nutrients and growth factors to survive; however, extended periods of ischemia (during which all available substrates for survival are depleted) ultimately result in cell death. Autophagy was first described in 1962 but not within the context of ischemia-reperfusion injury or cardiac tissues [82]; three different types (i.e. macro-, micro-autophagy, chaperone-mediated autophagy) have been identified [83]. Of note, the process of autophagy is mediated by a host of triggers and stimulators, sensors and genetic regulators that have been linked to cellular injury and necrosis in the pathogenesis of myocardial infarction. The contribution of autophagy to myocyte death following ischemia-reperfusion remains to be established; however, it probably plays a role in ventricular remodeling following restoration of perfusion to the ischemic tissue bed. Since myocytes are terminally differentiated and do not divide, salvage remains the ultimate goal in order to ensure restoration of contractile function. Interestingly, some studies report that a small percentage of myocytes can be renewed depending on age and that fewer than $50 \%$ of cardiomyocytes are exchanged during a normal life span [84-88]; their potential contribution to overall cardiac performance is not known.

Piot and co-workers documented a close relation between infarct development and DNA fragmentation suggesting that necrosis and apoptosis pathways were interrelated $[89,90]$. More recently, Buja and Weerasinghe proposed a hybrid model whereby apoptotic and oncotic pathways could both be activated in cardiocytes during ischemia [91]. This hypothesis is based on the intracellular availability of ATP; lethal injury would progress along an apoptotic pathway depending on residual ATP levels within the affected myocytes, along an oncotic pathway when ATP levels were exhausted and finally via activation of multiple intracellular death pathways. They also indicated that in contrast to classical apoptosis, lethally injured myocytes did not undergo rapid fragmentation and removal but developed secondary changes that triggered inflammation pathways. In our laboratory (unreported findings), we were unable to document significant DNA fragmentation or poly-[ADP-ribose]-polymerase (PARP) cleavage in rabbits subject to up to 120 minutes acute coronary occlusion followed by up to 96 hours reperfusion. Under normal conditions, PARP initiates energy consuming DNA repair by catalyzing ADPribosylation of nuclear proteins that results in a rapid depletion of intracellular NAD+ and high-energy phosphate stores. Our findings suggested that apoptosis was not an important contributor to ischemic cell death; however, others have reported significant apoptosis in rabbits subject to 30 in coronary occlusion followed by 4 hours reperfusion [92,93]. It is possible that myocytes not yet rendered irreversibly injured within the ischemic zone might be open targets for either apoptotic or oncotic pathways even after restoration of blood flow to the ischemic zone.

Vascular apoptosis might also be an important component of reperfusion injury but has not received a great deal of attention for various reasons (primarily due to lack of methods to confirm its presence). Apoptosis is associated with various cardiovascular risk factors, hypertension and hypercholesterolemia and may thereby be indirectly associated with physiopathology of syndromes that develop from coronary disease (i.e. infarction, heart failure, etc.) [94]. Finding apoptosis in coronary vessels after restoration of patency to the infarctrelated artery is tricky and this has led to the impression that it does not contribute significantly to coronary pathogenesis. However, in animal studies apoptosis has been documented in neointima and vascular smooth muscle after balloon injury or stent placement, which suggests that it may be an important factor in restenosis $[95,96]$. During ischemia a plethora of endogenous compounds that activate, or 
play a role in, cellular protective (anti-apoptotic) or destructive (proapoptotic) pathways are released from different cell types. Whether apoptosis is important in the physiopathology of post-ischemic myocardial injury is debatable but the question does merit some consideration since reinstatement of blood flow is a primary requirement for recovery of cardiac contractile function.

\section{Myocardial Protection Strategies}

Post-ischemic myocardial injury continues to be an important factor for patient mortality and morbidity. Consequently, limitation of infarct size after an acute coronary event is crucial to improve clinical outcomes in these patients. Development of pharmacologic, as well as non-pharmacologic interventions designed to delay loss of cardiocytes, vascular endothelial cells and smooth muscle, and neurons has been an ongoing challenge for almost a half-century. Though progress from basic science and clinical studies, particularly with respect to understanding mechanisms involved in cell injury and death, has been made significant work still needs to be done.

Timing of any reperfusion intervention is crucial; the original concept that 'time is muscle' has been adapted to include the microvasculature and microvascular perfusion. Establishing when lethal ischemic injury commences in humans is essentially impracticable (regardless of improvements in imaging techniques) but it stands to reason that early, rather than late, reperfusion therapy increases the potential to salvage myocardium [42,97,98]. However, in patients with small infarcts and STEMI (ST segment elevation myocardial infarction) myocardial salvage may be more difficult to demonstrate since the benefits of treatment may be small. Additionally, establishing when and if, reperfusion injury actually exists needs to be confirmed. The failure to reduce infarct size in humans after successful reperfusion of the infarct-related artery suggests that reperfusion injury might not occur or that it might not be preventable. Ndrepepa et al. recently proposed that preventive therapies against ischemic injury fail because they cannot prevent cell death within a zone of irreversible ischemic injury even though they may postpone timing of cell death [99]. Gersh and colleagues proposed that a golden window of opportunity' to limit myocardial injury existed within the initial 2-3 hours after onset of cardiac symptoms; the duration of this critical period is affected by the presence of functional coronary collateral vessels, myocardial oxygen demands, etc. [100]. At present, the potential contribution of late reperfusion therapy to mortality reduction is debatable.

Challenges remain apropos translation of cytoprotection strategies from experimental to clinical practice. Hundreds of interventions have been performed in experimental studies with a view to limit ischemic injury but to date, interventions intended to improve patient outcomes have been disappointing. This may be due to various factors including, among others, poorly designed pre-clinical studies prior to embarking on clinical trials, inadequate pharmacological studies, complexities of the human in vivo model, and inadequate design of clinical studies to test cell protection therapies [101-104]. A short summary of emerging treatments is provided here; however, we recommend the reader consult the wealth of scientific publications on this subject already available in the literature.

\section{Pharmacologic approach}

Since possible reperfusion injury occurs when blood flow to the infarct-related artery is restored, it would seem logical to initiate pharmacotherapy at, or just before, reperfusion. Which endogenous mechanisms, intracellular signalling pathways, or end-effectors of protection, etc. should be targeted? Important endogenous protective mechanisms include adenosine production, opening of ATP-sensitive potassium channels (KATP), release of nitric oxide, etc. [105,106]. Ischemia induces release of autocoids that activate complex intracellular signalling pathways some of which interconnect at the level of the mitochondria. For instance, several mitochondrial pathways involve the mitochondrial Permeability Transition Pore (mPTP) that is an important pathway for cell death [107-110]. In addition, mitochondrial, and sarcolemmal KATP channels are also potential cellular protection targets and continue to be evaluated in clinical studies [101,111]. Adenosine receptors (A1 and A2 subtypes) as well as protein kinase $\mathrm{C}$ receptors also continue to be targeted [112-115]; mitogen activated protein kinase blockers have also been evaluated [116,117]. Pharmacologic treatments aimed at the Reperfusion Injury Salvage Kinase (RISK) and Survivor Activating Factor Enhancement (SAFE) pathways that activate pro-survival pathways possibly by inhibiting opening of $\mathrm{mPTP}$ at the level of the mitochondria are being studied [111,118-121]. In fact, preliminary findings supporting the concept of reperfusion injury have been provided using the $\mathrm{mPTP}$ inhibitor, cyclosporine; administration prior to reperfusion by percutaneous coronary intervention (PCI) markedly reduced infarct size in patients [122]. Another cytoprotective kinase, 5' adenosine monophosphate-activated protein kinase (AMPK) is activated by ischemia; it regulates glucose and fatty acid metabolism by stimulating glycolysis, glucose uptake and fatty acid oxidation $[5,123,124]$. Nitric oxide may decrease reperfusion injury by stabilizing endothelial function and thereby maintaining blood flow, and by preventing activation of inflammation [125], it might also exert direct beneficial effects on myocyte survival (independent of endothelial cells) via opening of KATP channels [126]. These cardioprotective effects probably depend on nitric oxide bioavailability; however, in excess nitric oxide can also exert marked deleterious effects.

\section{Non-pharmacologic approach}

While primary PCI is the benchmark and preferred intervention for reperfusion of the infarct-related artery, it may not always be accessible to patients due, in part, to geographic location of interventional hospitals, etc. Prolonged treatment delays during transfer of patients between non-interventional and interventional hospitals considerably increase mortality risk since 'time is muscle'. As a result, there is an increasing utilisation of combined pharmacological treatment with mechanical reperfusion, also known as 'facilitated PCI' to establish early reperfusion [127]. Prognosis (i.e. in-hospital outcome and survival) in patients with STEMI improved markedly when they arrived at hospital with already open, compared to closed, infarctrelated vessels [128-130]. Further investigations are ongoing to evaluate benefits and safety when PCI is combined with a host of pharmacologic compounds compared to PCI alone; results will help establish guidelines to improve clinical outcomes.

An additional complication of PCI after successful opening of a major coronary vessel is the release from the ruptured atherosclerotic lesion of particulate debris that inevitably occludes downstream microcirculation to provoke cellular damage [131]; soluble vasoactive compounds are also released from vascular endothelium following PCI that could cause additional injury [61,62,98,132]. Mechanical thrombectomy systems (i.e. passive aspiration, active mechanical catheters, etc.) that help to prevent distal embolization of 
atherothrombotic debris during PCI and limiting injury have been quite successful [133-137].

Activation of endogenous cellular protective pathways during ischemia-reperfusion has also received widespread attention; more than 30 years ago, Murry and colleagues described ischemic preconditioning' [138]. Briefly, repeated cycles of ischemia of short duration followed by reperfusion prior to a prolonged coronary occlusion markedly limited cellular injury (i.e. infarct size, arrhythmias, endothelial dysfunction, etc.). Ongoing studies are looking at potential mechanisms responsible for cytoprotection (i.e. multiple receptor dependent and independent triggers, mediators and end-effectors [139]); a detailed examination of these studies is beyond the scope of this review. Several thousand studies reported since have documented the cytoprotective efficacy of conditioning strategies (pre, per, post, remote, etc.) in a host of experimental models [121,140-142]. Low-pressure reperfusion (variant of post-conditioning) at the time of reperfusion also merits consideration for post-ischemic myocyte protection [143]. However, cytoprotection potential of these interventions in humans remains controversial [144,145].

\section{Conclusion}

Although reperfusion strategies clearly improve patient outcomes, no clear consensus is available regarding the existence of reperfusion injury. Several examples of reperfusion injury including myocardial and vascular stunning, no-reflow and reperfusion arrhythmias have been discussed in a large number of experimental and clinical studies yet clear demonstration of its existence is not yet forthcoming. The physiopathology of ischemic injury is multifactorial and complicated (more so, in the presence of comorbidities); however, progress is being made and a considerable variety of therapeutic interventions (pharmacologic and non-pharmacologic) continue to be investigated. Understanding mechanisms that contribute to cellular injury and death remains a worthy challenge. However, numerous questions still need to be resolved to determine timing and best practices to improve clinical outcomes. For the moment, early restoration of patency to the infarct-related artery remains the only intervention capable of attenuating infarct development and potentially salvaging reversibly injured myocardium. Ultimately, determining whether reperfusion injury exists may be irrelevant if timing of therapeutic interventions cannot be instituted early enough to reduce or delay development of cellular damage.

\section{References}

1. Braunwald E, Kloner RA (1982) The stunned myocardium:prolonged, postischemic ventricular dysfunction. Circulation 66: 1146-1149.

2. Braunwald E, Kloner RA (1985) Myocardial reperfusion: A double-edged sword. J Clin Invest 76: 1713-1719.

3. Jennings RB (2013) Historical perspective on the pathology of myocardial ischemia/reperfusion injury. Circ Res 113: 428-438.

4. Kloner RA (1993) Does reperfusion injury exist in humans. J Am Coll Cardiol 21: 537-545.

5. Sharma V, Bell RM, Yellon DM (2012) Targeting reperfusion injury in acute myocardial infarction: a review of reperfusion injury pharmacotherapy. Expert Opin Pharmacother 13: 1153-1175.

6. Kloner RA, Jennings RB (2001) Consequences of brief ischemia: stunning, preconditioning, and their clinical implications: part 1 . Circulation 104: 2981-2989.

7. Kloner RA, Jennings RB (2001) Consequences of brief ischemia: stunning, preconditioning, and their clinical implications: part 2 . Circulation 104: 3158-3167.
8. Burke AP, Virmani R (2007) Pathophysiology of acute myocardial infarction. Med Clin North Am 91: 553-572.

9. Jennings RB, Somers HM, Smyth GA, Flack HA, Linn H (1960) Myocardial necrosis induced by temporary occlusion of a coronary artery in the dog. Arch Pathol 70: 68-78.

10. Jennings RB, Ganote CE (1974) Structural changes in myocardium during acute ischemia. Cardiovasc Res 35: 156-172.

11. Leist M, Single B, Castoldi AF, Kuhnle S, Nicotera P (1997) Intracellular adenosine triphosphate (ATP) concentration: a switch in the decision between apoptosis and necrosis. J Exp Med 185: 1481-1486.

12. Jennings RB, Reimer KA, Hill ML, Mayer SE (1981) Total ischemia in dog hearts in vitro: 1.comparison of high energy phosphate production, utilization and depletion and of adenosine nucleotide catabolism in total ischemia versus severe ischemia in vivo. Circ Res 49: 892-900.

13. Reimer KA, Jennings RB, Hill ML (1981) Total ischemia in dog hearts in vitro: 2.High energy phosphate depletion and associated defects in energy metabolism, cell volume regulation and sarcolemmal integrity. Circ Res 49: 901-911.

14. Xia P, Liu Y, Cheng Z (2016) Signaling Pathways in Cardiac Myocyte Apoptosis. Biomed Res Int 2016: p9583268.

15. Hotchkiss RS, Strasser A, McDunn JE, Swanson PE (2009) Cell death. N Engl J Med 361: 1570-1583.

16. Reimer KA, Lowe JE, Rasmussen MM, Jennings RB (1977) The wavefront phenomenon of ischemic cell death: I. Myocardial infarct size vs. duration of coronary occlusion in dogs. Circulation 56: 786-794.

17. Reimer KA, Jennings RB (1979) The "wavefront phenomenon" of myocardial ischemic cell death: II. Transmural progression of necrosis within the framework of ischemic bed size (myocardium at risk) and collateral flow. Lab Invest 40: 633-644.

18. Yellon DM, Hearse DJ, Crome R, Wyse RKH (1983) Temporal and spatial characteristics of evolving cell injury during regional myocardial ischemia in the dog: the "border zone" controversy. J Am Coll Cardiol 2: 661-670.

19. Hearse DJ, Crome R, Yellon DM, Wyse R (1983) Metabolic and flow correlates of myocardial ischaemia. Cardiovasc Res 17: 452-458.

20. Kingma JG, Simard D, Rouleau JR (2017) Influence of cardiac nerve status on cardiovascular regulation and cardioprotection. World Journal of Cardiology 9: 508-520.

21. Gourine A, Gourine AV (2014) Neural mechanisms of cardioprotection. Physiology 29: 133-140.

22. Janes RD, Johnstone DE, Armour JA (1987) Functional integrity of intrinsic cardiac nerves located over an acute transmural myocardial infarction. Can J Physiol Pharmacol 65: 64-69.

23. Krogh A (1919) The supply of oxygen to the tissues and the regulation of the capillary circulation. J Physiol 52: 457-474.

24. Davies PF, Tripathi SC (1993) Mechanical stress mechanisms and the cell. An endothelial paradigm. Circ Res 72: 239-245.

25. Zarins CK, Zatina MA, Giddens DP, Ku DN, Glagov S (1987) Shear stress regulation of artery lumen diameter in experimental atherogenesis. J Vasc Surg 5: 413-420.

26. Popel AS, Johnson PC (2005) Microcirculation and Hemorheology. Annu Rev Fluid Mech 37: 43-69.

27. Waters SL, Alastruey J, Beard DA, Bovendeerd PH, Davies PF, et al Theoretical models for coronary vascular biomechanics: progress \& challenges. Prog Biophys Mol Biol 104: 49-76.

28. Tateishi N, Suzuki Y, Soutani M, Maeda N (1994) Flow dynamics of erythrocytes in microvessels of isolated rabbit mesentery: cell-free layer and flow resistance. J Biomech 27: 1119-1125.

29. Seiler C (2010) The human coronary collateral circulation. Eur J Clin Invest 40: 465-476.

30. Seiler C (2003) The human coronary collateral circulation. Heart 89 1352-1357.

31. Kersten JR, Warltier DC (1995) Modulation of coronary collateral angiogenesis: a canine model of neovascularization induced by chronic ischemia. J Card Surg 10: 354-357. 
32. Kersten JR, Pagel PS, Chilian WM, Warltier DC (1999) Multifactoria basis for coronary collateralization: a complex adaptive response to ischemia. Cardiovasc Res 43: 44-57.

33. Stahl LD, Aversano TR, Becker LC (1986) Selective enhancement of function of stunned myocardium by increased flow. Circulation 74 : 843-851.

34. Kingma JG (2013) The myocardial microcirculation: A key target for salvaging ischemic myocardium. World Journal of Cardiovascular Diseases 3: 8-16.

35. Sakata Y, Kodama K, Kitakaze M, Masuyama T, Hirayama A, et al. (1997) Different mechanisms of ischemic adaptation to repeated coronary occlusion in patients with and without recruitable collateral circulation. J Am Coll Cardiol 30: 1679-1686.

36. Rentrop KP, Cohen M, Blanke H, Phillips RA (1985) Changes in collateral channel filling immediately after controlled coronary artery occlusion by an angioplasty balloon in human subjects. J Am Coll Cardiol 5: 587-592.

37. Billinger M, Fleisch M, Eberli FR, Garachemani A, Meier B, et al. (1999) Is the development of myocardial tolerance to repeated ischemia in humans due to preconditioning or to collateral recruitment. J Am Coll Cardiol 33: 1027-1035.

38. Tomai F, Crea F, Gaspardone A, Versaci F, Ghini AS, et al. (1999) Effects of naloxone on myocardial ischemic preconditioning in humans. J Am Coll Cardiol 33: 1863-1869.

39. Hale SL, Kloner RA (1999) Ischemic preconditioning and myocardia hypothermia in rabbits with prolonged coronary artery occlusion. Am J Physiol 276: 2029-2034.

40. Loke KE, Woodman OL (1998) Preconditioning improves myocardial function and reflow, but not vasodilator reactivity, after ischaemia and reperfusion in anaesthetized dogs. Clin Exp Pharmacol Physiol 25: 552-558.

41. Woodman OL (1999) Approaches to the prevention of coronary vascular dysfunction caused by myocardial ischaemia and reperfusion. Curr Pharm Des 5: 1077-1087.

42. Hausenloy DJ, Yellon DM (2013) Myocardial ischemia-reperfusion injury: a neglected therapeutic target. J Clin Invest 123: 92-100.

43. Heyndrick GR, Millard RW, McRitchie RJ, Maroko PR, Vatner SF (1975) Regional myocardial functional and electrophysiological alterations after brief coronary artery occlusion in conscious dogs. J Clin Invest 56: 978-985.

44. Bolli R, Jeroudi MO, Patel BS, Aruoma OI, Halliwell B, et al. (1989) Marked Reduction of Free Radical Generation and Contractile Dysfunction by Antioxidant Therapys Begun at the Time of Reperfusion. Circ Res 65: 607-622.

45. Bolli R (1990) Mechanism of myocardial "stunning". Circulation 82: 723-738.

46. Piper HM, Siegmund B, Ladilov YV, Schluter KD (1996) Myocardial protection during reperfusion. Thorac Cardiovasc Surg 44: 15-19.

47. Kloner RA, Ganote CE, Jennings RB (1974) The "no-reflow" phenomenon after temporary coronary occlusion in the dog. J Clin Invest 54 1496-1508.

48. Summers WK, Jamison RL (1971) The no reflow phenomenon in renal ischemia. Lab Invest 25: 635-643.

49. Ames A, Wright RL, Kowada M, Thurston JM, Majno G (1968) Cerebral ischemia. II. The no-reflow phenomenon. Am J Pathol 52: 437-453.

50. Ambrosio G, Weisman HF, Mannisi JA, Becker LC (1989) Progressive impairment of regional myocardial perfusion after initial restoration of postischemic blood flow. Circulation 80: 1846-1861.

51. Jeremy RW, Links JM, Becker LC (1990) Progressive failure of coronary flow during reperfusion of myocardial infarction: documentation of the no reflow phenomenon with positron emission tomography. J Am Coll Cardiol 16: 695-704.

52. Kloner RA, Alker KJ (1984) The effect of streptokinase on intramyocardial hemorrhage, infarct size, and the no-reflow phenomenon during coronary reperfusion. Circulation 70: 513-521.
53. Kloner RA, Rude RE, Carlson N, Maroko PR, DeBoer LWV, et al. Ultrastructural evidence of microvascular damage and myocardial cell injury after coronary artery occlusion: Which comes first. Circulation 62: 945-952.

54. Reffelmann T, Kloner RA (2002) Microvascular reperfusion injury: rapid expansion of anatomic no reflow during reperfusion in the rabbit. Am J Physiol Heart Circ Physiol 283: 1099-1107.

55. Reffelmann T, Kloner RA (2002) The "no-reflow" phenomenon: basic science and clinical correlates. Heart 87: 162-168.

56. Tsao PS, Aoki N, Lefer DJ, Johnson G, Lefer AM (1990) Time course of endothelial dysfunction and myocardial injury during myocardial ischemia and reperfusion in the cat. Circulation 82: 1402-1412.

57. VanBenthuysen KM, McMurtry IF, Horwitz LD (1987) Reperfusion after acute coronary occlusion in dogs impairs endothelium-dependent relaxation to acetylcholine and augments contractile reactivity in vitro. J Clin Invest 79: 265-274.

58. Bolli R, Triana JF, Jeroudi MO (1990) Prolonged impairmant of coronary vasodilatation after reversible ischemia: evidence for microvascular "stunning". Circ Res 67: 332-343.

59. Kloner RA (2011) No-reflow phenomenon: maintaining vascular integrity. J Cardiovasc Pharmacol Ther 16: 244-250.

60. Vinten-Johansen J (2004) Involvement of neutrophils in the pathogenesis of lethal myocardial reperfusion injury. Cardiovasc Res 61: 481-97.

61. Leineweber K, Bose D, Vogelsang M, Haude M, Erbel R, et al. (2006) Intense vasoconstriction in response to aspirate from stented saphenous vein aortocoronary bypass grafts. J Am Coll Cardiol 47: 981-986.

62. Kleinbongard P, Bose D, Baars T, Mohlenkamp S, Konorza T, et al. Vasoconstrictor potential of coronary aspirate from patients undergoing stenting of saphenous vein aortocoronary bypass grafts and its pharmacological attenuation. Circ Res 108: 344-352.

63. Heusch G, Kleinbongard P, Skyschally A, Levkau B, Schulz R, et al. (2012) The coronary circulation in cardioprotection: more than just one confounder. Cardiovasc Res 94: 237-245.

64. Babu GG, Walker JM, Yellon DM, Hausenloy DJ (2011) Peri-procedural myocardial injury during percutaneous coronary intervention: an important target for cardioprotection. Eur Heart J 32: 23-31.

65. Skyschally A, Walter B, Heusch G (2013) Coronary microembolization during early reperfusion: infarct extension, but protection by ischaemic postconditioning. Eur Heart J 34: 3314-3321.

66. Whittaker P, Przyklenk K (1994) Reduction of infarct size in vivo with ischemic preconditioning: mathematical evidence for protection via nonischemic tissue. Basic Res Cardiol 89: 6-15.

67. Dorge H, Neumann T, Behrends M, Skyschally A, Schulz R, et al. (2000) Perfusion-contraction mismatch with coronary microvascular obstruction: role of inflammation. Am J Physiol Heart Circ Physiol 279: 2587-2592.

68. Niccoli G, Lanza GA, Shaw S, Romagnoli E, Gioia D, et al. (2006) Endothelin-1 and acute myocardial infarction: a no-reflow mediator after successful percutaneous myocardial revascularization. Eur Heart J 27: 1793-1798.

69. Porto I, Biasucci LM, De Maria GL, Leone AM, Niccoli G, et al. (2012) Intracoronary microparticles and microvascular obstruction in patients with ST elevation myocardial infarction undergoing primary percutaneous intervention. Eur Heart J 33: 2928-29.

70. Kloner RA, Fishbein MC, Hare CM, Maroko PR (1979) Early ischemic ultrastructural and histochemical alterations in the myocardium of the rat following coronary artery occlusion. Exp Mol Pathol 30: 129-1243.

71. Schweichel JU, Merker HJ (1973) The morphology of various types of cell death in prenatal tissues. Teratology 7: 253-266.

72. Galluzzi L, Bravo-San Pedro JM, Vitale I, Aaronson SA, Abrams JM, et al. (2015) Essential versus accessory aspects of cell death: recommendations of the NCCD 2015. Cell Death Differ 22: 58-73.

73. Malhi H, Gores GJ, Lemasters JJ (2006) Apoptosis and necrosis in the liver: a tale of two deaths. Hepatology 43: 31-44. 
74. Ashkenazi A, Dixit VM (1998) Death receptors: signaling and modulation. Science 281: 1305-1308.

75. Haunstetter A, Izumo S (1998) Apoptosis: basic mechanisms and implications for cardiovascular disease. Circ Res 82: 1111-1129.

76. Gustafsson AB, Gottlieb RA (2008) Heart mitochondria: gates of life and death. Cardiovasc Res 77: 334-343.

77. Scarabelli TM, Gottlieb RA (2004) Functional and clinical repercussions of myocyte apoptosis in the multifaceted damage by ischemia/reperfusion injury: old and new concepts after 10 years of contributions. Cell Death Differ 2: 144-152.

78. Moe GW, Marin-Garcia J (2016) Role of cell death in the progression of heart failure. Heart Fail Rev 21: 157-167.

79. Ohno M, Takemura G, Ohno A, Misao J, Hayakawa Y, et al. (1998) "Apoptotic" myocytes in infarct area in rabbit hearts may be oncotic myocytes with DNA fragmentation. Analysis by immunogold electron microscopy combined with in situ nick end-labelling. Circulation 98: 1422-1430.

80. Buja LM, Vela D (2008) Cardiomyocyte death and renewal in the normal and diseased heart. Cardiovasc Pathol 17: 349-374.

81. Takemura G, Fujiwara H (2006) Morphological aspects of apoptosis in heart diseases. J Cell Mol Med 10: 56-75.

82. Ashford TP, Porter KR (1962) Cytoplasmic components in hepatic cell lysosomes. J Cell Biol 12: 198-202.

83. Thapalia BA, Zhou Z, Lin X (2014) Autophagy, a process within reperfusion injury: an update. Int J Clin Exp Pathol 7: 8322-8341.

84. Bergmann O, Bhardwaj RD, Bernard S, Zdunek S, Barnabe-Heider F, et al. (2009) Evidence for cardiomyocyte renewal in humans. Science 324: 98-102.

85. Eschenhagen T, Bolli R, Braun T, Field LJ, Fleischmann BK, et al. (2017) Cardiomyocyte Regeneration: A Consensus Statement. Circulation 136: 680-686.

86. Ali SR, Hippenmeyer S, Saadat LV, Luo L, Weissman IL, et al. (2014) Existing cardiomyocytes generate cardiomyocytes at a low rate after birth in mice. Proc Natl Acad Sci 111: 8850-8855.

87. Kimura W, Xiao F, Canseco DC, Muralidhar S, Thet S, et al. (2015) Hypoxia fate mapping identifies cycling cardiomyocytes in the adult heart. Nature 523: 226-230.

88. Senyo SE, Steinhauser ML, Pizzimenti CL, Yang VK, Cai L, et al. (2013) Mammalian heart renewal by pre-existing cardiomyocytes. Nature 493: 433-466.

89. Piot CA, Padmanaban D, Ursell PC, Sievers RE, Wolfe C (1997) Ischemic preconditioning decreases apoptosis in rat hearts in vivo. Circulation 96: 1598-1604.

90. Piot CA, Martini JF, Bui SK, Wolfe CL (1999) Ischemic preconditioning attenuates ischemia/reperfusion-induced activation of caspases and subsequent cleavage of poly(ADP-ribose) polymerase in rat hearts in vivo. Cardiovasc Res 44: 536-542.

91. Buja LM, Weerasinghe P (2010) Unresolved issues in myocardial reperfusion injury. Cardiovasc Pathol 19: 29-35.

92. Gottlieb RA, Burleson KO, Kloner RA, Babior BM, Engler RL (1994) Reperfusion injury induces apoptosis in rabbit cardiomyocytes. J Clin Invest 94: 1621-1628.

93. Gottlieb RA, Gruol DE, Zhu JY, Engler RL (1996) Preconditioning in rabbit cardiomyocytes: role of $\mathrm{pH}$, vacuolar proton ATPase, and apoptosis. J Clin Invest 97: 2391-2398.

94. Best PJ, Hasdai D, Sangiorgi G, Schwartz RS, Holmes DR, et al. (1999) Apoptosis. Basic concepts and implications in coronary artery disease. Arterioscler Thromb Vasc Biol 19: 14-22.

95. Perlman H, Maillard L, Krasinski K, Walsh K (1997) Evidence for the rapid onset of apoptosis in medial smooth muscle cells after balloon injury. Circulation 95: 981-987.

96. Kollum M, Kaiser S, Kinscherf R, Metz J, Kubler W, et al. Apoptosis after stent implantation compared with balloon angioplasty in rabbits. Role of macrophages. Arterioscler Thromb Vasc Biol 17: 2383-2388.
97. Ferdinandy P, Hausenloy DJ, Heusch G, Baxter GF, Schulz R (2014) Interaction of risk factors, comorbidities, and comedications with ischemia/reperfusion injury and cardioprotection by preconditioning, postconditioning, and remote conditioning. Pharmacol Rev 66: 1142-1174.

98. Prasad A, Stone GW, Holmes DR, Gersh B (2009) Reperfusion injury, microvascular dysfunction, and cardioprotection: the "dark side" of reperfusion. Circulation 120: 2105-2112.

99. Ndrepepa G, Colleran R, Kastrati A (2017) Reperfusion injury in STsegment elevation myocardial infarction: the final frontier. Coron Artery Dis 28: 253-262.

100. Gersh BJ, Stone GW, White HD, Holmes DR (2005) Pharmacological facilitation of primary percutaneous coronary intervention for acute myocardial infarction: is the slope of the curve the shape of the future. JAm Med Assoc. 293: 979-986.

101. Hausenloy DJ, Baxter G, Bell R, Botker HE, Davidson SM, et al. Translating novel strategies for cardioprotection: the Hatter Workshop Recommendations. Basic Res Cardiol 105: 677-686.

102. Lecour S, Botker HE, Condorelli G, Davidson SM, Garcia-Dorado D, et al. (2014) ESC working group cellular biology of the heart: position paper: improving the preclinical assessment of novel cardioprotective therapies. Cardiovasc Res 104: 399-411.

103. Schwartz Longacre L, Kloner RA, Arai AE, Baines CP, Bolli R, et al. (2011) New horizons in cardioprotection: recommendations from the 2010 National Heart, Lung, and Blood Institute Workshop. Circulation 124: 1172-1179.

104. Verma S, Fedak PW, Weisel RD, Butany J, Rao V, et al. (2002) Fundamentals of reperfusion injury for the clinical cardiologist. Circulation 105: 2332-2336.

105. Przyklenk K (2001) Pharmacologic treatment of the stunned myocardium: the concepts and the challenges. Coron Artery Dis 12: 363-369.

106. Canyon SJ, Dobson GP (2005) Pretreatment with an adenosine Al receptor agonist and lidocaine: a possible alternative to myocardial ischemic preconditioning. J Thorac Cardiovasc Surg 130: 371-377.

107. Giblett JP, West NE, Hoole SP (2014) Cardioprotection for percutaneous coronary intervention-reperfusion quality as well as quantity. Int $J$ Cardiol 177: 786-793.

108. Botker HE (2015) Mitochondrial care in acute myocardial infarction. Eur Heart J 36: 77-79.

109. Chakrabarti AK, Feeney K, Abueg C, Brown DA, Czyz E, et al. (2013) Rationale and design of the EMBRACE STEMI study: a phase 2a, randomized, double-blind, placebo-controlled trial to evaluate the safety, tolerability and efficacy of intravenous Bendavia on reperfusion injury in patients treated with standard therapy including primary percutaneous coronary intervention and stenting for ST-segment elevation myocardial infarction. Am Heart J 165: 509-514.

110. Atar D, Arheden H, Berdeaux A, Bonnet JL, Carlsson M, et al. (2015) Effect of intravenous TRO40303 as an adjunct to primary percutaneous coronary intervention for acute ST-elevation myocardial infarction: MITOCARE study results. Eur Heart J 36: 112-119.

111. Kitakaze M, Asakura M, Kim J, Shintani Y, Asanuma H, et al. (2007) Human atrial natriuretic peptide and nicorandil as adjuncts to reperfusion treatment for acute myocardial infarction (J-WIND): two randomised trials. Lancet 370: 1483-1493.

112. Ross AM, Gibbons RJ, Stone GW, Kloner RA, Alexander RW (2005) A randomized, double-blinded, placebo-controlled multicenter trial of adenosine as an adjunct to reperfusion in the treatment of acute myocardial infarction (AMISTAD-II). J Am Coll Cardiol 45: 1775-1780.

113. Kloner RA, Forman MB, Gibbons RJ, Ross AM, Alexander RW, et al. (2006) Impact of time to therapy and reperfusion modality on the efficacy of adenosine in acute myocardial infarction: the AMISTAD-2 trial. Eur Heart J 27: 2400-2405.

114. Forman MB, Stone GW, Jackson EK (2006) Role of adenosine as adjunctive therapy in acute myocardial infarction. Cardiovasc Drug Rev 24: 116-147. 
115. Inagaki K, Chen L, Ikeno F, Lee FH, Imahashi K, et al. (2003) Inhibition of delta-protein kinase $\mathrm{C}$ protects against reperfusion injury of the ischemic heart in vivo. Circulation 108: 2304-2307.

116. See F, Thomas W, Way K, Tzanidis A, Kompa A, et al. (2004) p38 mitogen-activated protein kinase inhibition improves cardiac function and attenuates left ventricular remodeling following myocardial infarction in the rat. J Am Coll Cardiol 44: 1679-1689.

117. Newby LK, Marber MS, Melloni C, Sarov BL, Aberle LH, et al. (2014) Losmapimod, a novel p38 mitogen-activated protein kinase inhibitor, in non-ST-segment elevation myocardial infarction: a randomised phase 2 trial. Lancet 384: 1187-1195

118. Hausenloy DJ, Duchen MR, Yellon DM (2003) Inhibiting mitochondrial permeability transition pore opening at reperfusion protects against ischaemia-reperfusion injury. Cardiovasc Res 60: 617-625.

119. Hausenloy DJ, Yellon DM (2003) The mitochondrial permeability transition pore: its fundamental role in mediating cell death during ischaemia and reperfusion. J Mol Cell Cardiol 35: 339-341.

120. Bell RM, Yellon DM (2003) Atorvastatin, administered at the onset of reperfusion, and independent of lipid lowering, protects the myocardium by up-regulating a pro-survival pathway. J Am Coll Cardiol 41: 508-515.

121. Hausenloy DJ, Barrabes JA, Botker HE, Davidson SM, Di Lisa F, et al (2016) Ischaemic conditioning and targeting reperfusion injury: a 30 year voyage of discovery. Basic Res Cardiol 111: 70.

122. Piot C, Croisille P, Staat P, Thibault H, Rioufol G, et al. (2008) Effect of cyclosporine on reperfusion injury in acute myocardial infarction. $\mathrm{N}$ Engl J Med 359: 473-481

123. Russell RR, Li J, Coven DL, Pypaert M, Zechner C, et al. (2004) AMPactivated protein kinase mediates ischemic glucose uptake and prevents postischemic cardiac dysfunction, apoptosis, and injury. J Clin Invest 114: 495-503.

124. Sambandam N, Lopaschuk GD (2003) AMP-activated protein kinase (AMPK) control of fatty acid and glucose metabolism in the ischemic heart. Prog Lipid Res 42: 238-256.

125. Vinten JJ, Zhao ZQ, Nakamura M, Jordan JE, Ronson RS, et al. (1999) Nitric oxide and the vascular endothelium in myocardial ischemiareperfusion injury. Ann N Y Acad Sci 874: 354-370.

126. Shiono N, Rao V, Weisel RD, Kawasaki M, Li RK, et al. (2002) L-arginine protects human heart cells from low-volume anoxia and reoxygenation. Am J Physiol Heart Circ Physiol 282: 805-815.

127. Brodie BR (2005) Facilitated percutaneous coronary intervention. Heart 91: 1527-1529.

128. Brodie BR, Stuckey TD, Hansen C, Muncy D (2000) Benefit of coronary reperfusion before intervention on outcomes after primary angioplasty for acute myocardial infarction. Am J Cardiol 85: 13-18.

129. Stone GW, Cox D, Garcia E, Brodie BR, Morice MC, et al. (2001) Normal flow (TIMI-3) before mechanical reperfusion therapy is an independent determinant of survival in acute myocardial infarction: analysis from the primary angioplasty in myocardial infarction trials. Circulation 104: 636-641.

130. Vermeer F, Oude OAJ, Berg EJ, Brunninkhuis LG, Werter CJ, et al. (1999) Prospective randomised comparison between thrombolysis, rescue
PTCA, and primary PTCA in patients with extensive myocardial infarction admitted to a hospital without PTCA facilities: a safety and feasibility study. Heart 82: 426-431.

131. Heusch G, Kleinbongard P, Bose D, Levkau B, Haude M, et al.(2009) Coronary microembolization: from bedside to bench and back to bedside. Circulation 120: 1822-1836.

132. Driesen RB, Zalewski J, Vanden DN, Vermeulen K, Bogaert J, et al.(2012) Histological correlate of a cardiac magnetic resonance imaged microvascular obstruction in a porcine model of ischemia-reperfusion. Cardiovasc Pathol 21: 129-131.

133. Srinivasan M, Rihal C, Holmes DR, Prasad A (2009) Adjunctive thrombectomy and distal protection in primary percutaneous coronary intervention: impact on microvascular perfusion and outcomes. Circulation 119: 1311-1319.

134. Svilaas T, Vlaar PJ, Van der Horst IC, Diercks GF, Smet BJ, et al. (2008) Thrombus aspiration during primary percutaneous coronary intervention. N Engl J Med 358: 557-567.

135. Vlaar PJ, Svilaas T, Van der Horst IC, Diercks GF, Fokkema ML, et al. (2008) Cardiac death and reinfarction after 1 year in the Thrombus Aspiration during Percutaneous coronary intervention in Acute myocardial infarction Study (TAPAS): a 1-year follow-up study. Lancet 371: 1915-1920.

136. Sardella G, Mancone M, Bucciarelli DC, Agati L, Scardala R, et al. (2009) Thrombus aspiration during primary percutaneous coronary intervention improves myocardial reperfusion and reduces infarct size: the EXPIRA (thrombectomy with export catheter in infarct-related artery during primary percutaneous coronary intervention) prospective, randomized trial. J Am Coll Cardiol 53:309-315.

137. Giglioli C, Cecchi E, Sciagra R, Baldereschi GJ, Meucci F, et al.(2016) Comparison between coronary thrombus aspiration with Angiojet(R) or $\operatorname{Export}(\mathrm{R})$ catheter in patients with ST-elevation myocardial infarction submitted to primary angioplasty: The COCOTH Study. Int J Cardiol 203: 757-762.

138. Murry CE, Jennings RB, Reimer KA (1986) Preconditioning with ischemia: a delay of lethal cell injury in ischemic myocardium. Circulation 74: 1124-1136.

139. Zhao ZQ, Vinten JJ (2006) Postconditioning: reduction of reperfusioninduced injury. Cardiovasc Res 70: 200-211.

140. Hausenloy DJ, Yellon DM (2016) Ischaemic conditioning and reperfusion injury. Nat Rev Cardiol 13: 193-209.

141. Kingma JG (2014) Conditioning strategies limit cellular injury? World Journal of Cardiovascular Diseases 4: 539-547.

142. Yellon DM, Downey JM (2003) Preconditioning the myocardium: from cellular physiology to clinical cardiology. Physiol Rev 83: 1113-1151.

143. Ferrera R, Benhabbouche S, Da Silva CC, Alam MR, Ovize M (2015) Delayed low pressure at reperfusion: A new approach for cardioprotection. J Thorac Cardiovasc Surg 150: 1641-1648.

144. Ovize M, Thibault H, Przyklenk K (2013) Myocardial conditioning: opportunities for clinical translation. Circ Res 113: 439-450.

145. Vander HRS, Steenbergen C (2013) Cardioprotection and myocardial reperfusion: pitfalls to clinical application. Circ Res 113: 464-477. 